\title{
Correction
}

\section{Correction to: The 2-Leg Vertex in K-theoretic DT Theory}

\author{
Ya. Kononov ${ }^{1,2}\left(\right.$, A. Okounkov ${ }^{1,2,3}$, A. Osinenko ${ }^{1}$ \\ ${ }^{1}$ Department of Mathematics, Columbia University, New York, USA. \\ E-mail: ya.kononoff@gmail.com; okounkov@math.columbia.edu; osinenko@ math.columbia.edu \\ 2 Center for Advanced Studies, Skoltech, Moscow, Russia. \\ ${ }^{3}$ Laboratory of Representation Theory and Mathematical Physics, HSE, Moscow, Russia. \\ Published online: 20 September 2021 - ( $)$ Springer-Verlag GmbH Germany, part of Springer Nature 2021
}

\section{Correction To: Commun. Math. Phys. 382, 1579-1599 (2021) https://doi.org/10.1007/s00220-021-03936-z}

The article [The 2-Leg Vertex in K-theoretic DT Theory], written by [Ya. Kononov, A. Okounkov, A. Osinenko,], was originally published electronically on the publisher's internet portal (currently Springerlink) on March 09, 2021 with open access.

With the author(s)' decision to step back from Open Choice the copyright of the article changed on (June 2021) to @Springer-Verlag GmbH Germany, part of Springer Nature 2021 and the article is forthwith distributed under the terms of copyright.

The original article has been corrected.

Publisher's Note Springer Nature remains neutral with regard to jurisdictional claims in published maps and institutional affiliations. 